\title{
LOS FONDOS EUROPEOS: SU GESTIÓN INSTRUMENTAL POR LOS ESTADOS MIEMBROS
}

\author{
Claudia Hernández López* \\ Universidad de La Laguna
}

\section{Resumen}

Los fondos europeos no solo son recursos destinados a financiar las políticas europeas; su evolución los ha transformado en poderosas herramientas de control e intervención. Cada vez más, los reglamentos que los regulan han ido limitando la autonomía de los Estados miembros y han convertido a sus Administraciones en meras gestoras de recursos. El presente trabajo analiza el impacto que tiene la normativa europea relativa a los fondos estructurales y de inversión sobre las Administraciones nacionales. En concreto, se estudia cómo la intensidad y extensión de la normativa pone en cuestión la operatividad de los principios de subsidiariedad y proporcionalidad, así como del principio de autonomía institucional y procedimental sobre el que descansa, en principio, la ejecución del Derecho de la UE.

Palabras clave: fondos europeos, autonomía, subsidiariedad, Estados miembros.

\section{THE EUROPEAN FUNDS: ITS INSTRUMENTAL MANAGEMENT \\ BY THE MEMBER STATES}

\section{Abstract}

European funds are not only resources destined to finance European policies; their evolution has transformed them into powerful control and intervention tools. Increasingly, the regulations that regulate them have been limiting the autonomy of the Member States and have turned their Administrations into mere resource managers. This paper analyzes the impact of European regulations on structural and investment funds on national administrations. In particular, it is studied how the intensity and extension of the regulation calls into question the operation of the principles of subsidiarity and proportionality, as well as the principle of institutional and procedural autonomy on which rests, in principle, the implementation of EU law.

KeYwords: European funds, autonomy, subsidiarity, Member States. 


\section{INTRODUCCIÓN}

Como es sabido, muchas de las políticas europeas deben su éxito a los fondos europeos ${ }^{1}$. La política agrícola común -PAC- u otras como la de cohesión o la social no pueden ser explicadas sin hacer referencia al Fondo Europeo de Orientación y Garantía Agrícola -FEOGA-2 ${ }^{2}$, al Fondo Europeo de Desarrollo Regional -FEDER_- ${ }^{3}$ o al Fondo Social Europeo -FSE- ${ }^{4}$. Los fondos europeos han sido, por tanto, uno de los mecanismos claves para la consecución de algunos de los grandes objetivos de la UE5.

Para que un Estado pueda ser receptor de fondos europeos debe adoptar multitud de medidas y cumplir exigencias de todo tipo. Hace décadas, las obligaciones impuestas a los Estados miembros eran mínimas e iban orientadas a garantizar

* Profesora de Derecho Administrativo de la ULL.

1 Aunque la expresión "fondos europeos» es muy amplia, normalmente se emplea para hacer referencia a los Fondos Estructurales y de Inversión Europeos -fondos EIE-, que son recursos que funcionan de modo conjunto con el fin de apoyar la cohesión económica, social y territorial; y a los instrumentos financieros de la política agrícola común -PAC-. Los fondos EIE son cinco: Fondo Europeo de Desarrollo Regional -FEDER-, Fondo Social Europeo -FSE-, Fondo de Cohesión -FC-, Fondo Europeo Agrícola de Desarrollo Rural -Feader- y Fondo Europeo Marítimo y de la Pesca-FEMP-. En períodos anteriores, las diferencias entre los fondos EIE y los de la PAC eran más grandes. Sin embargo, su regulación ha ido evolucionando y ha ganado uniformidad. De hecho, el Feader es uno de los fondos que tienen por objeto financiar la PAC, pero se integra en los fondos EIE y recibe un tratamiento normativo conjunto. Por ello, salvo algunas particularidades, su funcionamiento es idéntico a los fondos EIE.

${ }^{2}$ Creado por el Reglamento núm. 25, de 4 de abril, relativo a la financiación de la política agrícola común -DOCE núm. 30, de 20 de abril de 1962-. Actualmente el FEOGA se ha dividido en dos fondos distintos: Fondo Europeo Agrícola de Garantía -FEAGA- y Fondo Europeo Agrícola de Desarrollo Rural -Feader-. Regulados en el Reglamento (UE) 1306/2013 sobre la financiación, gestión y seguimiento de la Política Agrícola Común.

3 Se creó por medio del Reglamento (CEE) 724/1975, del Fondo Europeo de Desarrollo Regional. Forma parte de los fondos estructurales desde el año 1986. Actualmente se regula en Reglamento (UE) 1301/2013 relativo al Fondo Europeo de Desarrollo Regional y sobre disposiciones específicas relativas al objetivo de inversión en crecimiento y empleo.

${ }^{4}$ Se mencionó por primera vez en el Tratado Constitutivo (CEE) de 1957 -artículo 123-. La primera regulación específica al margen del Tratado fue el Reglamento del Consejo núm. 9 de 1960 -Règlement n. ${ }^{\circ} 9$ concernant le Fonds social europée, DOCE, núm. 56, 31 de agosto de 1960, pp. 1189 a 1198-. A raíz del acta única europea (1986) este fondo pasó a formar parte de los fondos estructurales. Actualmente se regula en el Reglamento (UE) 1304/2013 del Parlamento Europeo y del Consejo, de 17 de diciembre, relativo al Fondo Social Europeo.

5 Sobre los fondos europeos véase Ordońez Solís, D.: Fondos estructurales europeos. Régimen jurídico y gestión administrativa, Marcial Pons, 1997; del mismo autor, «La gestión de los Fondos Europeos», Revista de Derecho de la UE, núm. 20, 2011, pp. 117-149; Moreno Molina, A.M.: «Los medios económicos de la Administración pública comunitaria: la ejecución presupuestaria», Parejo Alfonso, L. y De la Quadra Salcedo Fernández del Castillo, T.: Manual de Derecho Administrativo Comunitario, Centro de Estudios Ramón Areces S.A., 2000, pp. 355-383; Molina del Pozo, C.F.: Derecho de la Unión Europea, Reus, 2015; Fuentetaja Pastor, J.A.: "Las competencias ejecutivas de la Administración europea en el ámbito de la Política Agrícola Común", Revista de Derecho de la UE, núm. 26, 2014, pp. 41-76; del mismo autor, Derecho Administrativo europeo, Civitas, 2015, entre otros. 
la correcta aplicación de los recursos. Sin embargo, en cada período esas obligaciones han ido en aumento ${ }^{6}$. Cada vez más, la UE ha profundizado en la regulación de todo aquello que tenga que ver con los fondos europeos - pagos, organización, correcciones de irregularidades, controles, acciones a financiar, etc.-, limitando, en consecuencia, la autonomía de los Estados miembros.

Esa fuerte intervención obedece, principalmente, a dos razones. La primera es el régimen de ejecución de los fondos. El hecho de que se ejecuten en régimen de gestión compartida hace que los Estados miembros tengan especial protagonismo en todas las tareas. Por ello, la UE regula la actividad de los Estados y los orienta. No obstante, debe señalarse que la tendencia ha sido la de regularlo todo y sujetar a los Estados a una estrecha supervisión.

La segunda razón es la reciprocidad implícita en los fondos europeos. El deseo de los Estados de acceder a la financiación los lleva a cumplir punto por punto con todos los requerimientos europeos. Esto ha sido aprovechado por la UE para establecer numerosas exigencias. El máximo exponente de ello se encuentra en los reglamentos del último período (2014-2020). Por primera vez, se vincula la recepción de los recursos a la gobernanza económica de la Unión. Ya no basta con cumplir las intensas exigencias relativas a la gestión y control de los fondos sino que, además, el Estado debe cumplir con requerimientos de carácter económico que nada tienen que ver con los fondos europeos ${ }^{7}$.

Lo apuntado permite afirmar que los fondos no son únicamente recursos destinados a financiar políticas europeas. También son poderosos mecanismos de control e intervención sobre los Estados miembros. La UE no se limita a regular aquellas cuestiones que requieran uniformidad, también considera necesario que todos los Estados ejecuten y apliquen el Derecho de la UE en los términos exactamente definidos en la normativa. El grado de intervención es tal que, en todo lo relativo a los fondos europeos, los Estados parecen haberse convertido en meros gestores de recursos.

Esto no solo invita a repensar el fin perseguido por los fondos, sino que permite cuestionar la operatividad de los principios de subsidiariedad y proporcionalidad que rigen el Derecho de la UE. Asimismo, pone en entredicho el principio de autonomía institucional y procedimental sobre el que descansa, en principio, la ejecución de los fondos europeos.

${ }^{6}$ Desde el Tratado de Lisboa de 2007 -TFUE- se ha blindado la planificación periódica dentro de la UE. El artículo 312 prevé que «el MFP se establecerá para un período mínimo de cinco años" y "tendrá por objeto garantizar la evolución ordenada de los gastos de la Unión dentro del límite de sus recursos propios [...] el presupuesto anual de la Unión respetará el Marco Financiero Plurianual». El régimen jurídico del período actual se encuentra establecido en las normas aprobadas para el período 2014-2020 y en el marco financiero plurianual-MFP-. Véase el Reglamento (UE) 1311/2013 del Consejo, de 2 de diciembre de 2013, por el que se establece el marco financiero plurianual para el período 2014-2020.

7 Sobre esto véase Fuentetaja Pastor, J.A.: Derecho Administrativo..., ob. cit., p. 534 y ss. 


\section{LAS CAUSAS DE LA INTERVENCIÓN EUROPEA: LA NECESIDAD DE CONSERVAR EL CONTROL TRAS EL PASO A LA GESTIÓN COMPARTIDA}

De acuerdo con el reglamento financiero, en adelante $\mathrm{REFIN}^{8}$, la ejecución del presupuesto de la UE se puede hacer directamente, indirectamente y de forma compartida. Las diferencias entre los distintos modos de ejecución se encuentran, principalmente, en la forma en la que intervienen las Administraciones implicadas.

En el régimen de ejecución directa el peso lo lleva la Comisión, que se encarga de ejecutar los fondos íntegramente por medio de sus servicios. Hace varias décadas su uso era frecuente para la ejecución de determinados fondos como el Fondo Social Europeo -FSE- en la década de los ochenta, o el Fondo Europeo de Desarrollo Regional-FEDER- en los setenta. Ello era posible porque el volumen de recursos canalizados era menor que el actual y el número de Estados implicados también.

Sin embargo, el crecimiento de la UE hizo que este sistema empezara a ser considerado como demasiado complejo y lento, por lo que se pasó a la ejecución en régimen de gestión compartida? . En esta modalidad la Comisión delega competencias en los Estados miembros. Por ello, son estos los que tienen el protagonismo en la ejecución ${ }^{10}$. Ahí está la clave: el hecho de que sean los Estados los que, por delegación, lleven el peso de la ejecución ha generado en los mismos importantes consecuencias derivadas de la exhaustiva regulación europea.

Si se analiza la evolución de los reglamentos relativos a los fondos, se puede observar que con la llegada de la ejecución compartida la normativa empieza a crecer. Cada vez se ahonda más en cuestiones que afectan a las Administraciones nacionales. El grado de detalle de la normativa es tan intenso que se observa cierta tendencia de la UE a ejercer un control absoluto sobre el papel de los Estados en la ejecución y gestión de los fondos. La UE no se limita a marcar unas directrices de actuación, sino que ha desarrollado un amplio marco normativo que afecta a todas y cada una

${ }^{8}$ Reglamento (UE) 966/2012 del Parlamento Europeo y del Consejo, de 25 de octubre de 2012, sobre las normas financieras aplicables al presupuesto general de la Unión y sus normas de desarrollo.

9 Para una explicación detallada del paso de un sistema a otro y las causas que lo motivaron véase Ordóńez Solís, D.: "La gestión de los fondos...», ob. cit., p. 126 y ss. De la utilización del régimen de ejecución compartida da cuenta el artículo 4.7 del Reglamento (UE) 1303/2013, que establece que «La parte del presupuesto de la Unión asignada a los Fondos EIE se ejecutará en el marco de la gestión compartida entre los Estados miembros y la Comisión, según lo dispuesto en el artículo 59 del Reglamento Financiero, a excepción del importe de la ayuda del Fondo de Cohesión transferido al Mecanismo "Conectar Europa" al que se refiere el artículo 92, apartado 6 del presente Reglamento, las acciones innovadoras a iniciativa de la Comisión conforme al artículo 8 del Reglamento del FEDER, la asistencia técnica a iniciativa de la Comisión y la ayuda a la gestión directa en virtud del Reglamento FEMP».

${ }^{10}$ Las previsiones del reglamento financiero en relación con la gestión compartida son completadas por los reglamentos de los fondos, en especial por el reglamento común a los fondos EIE -Reglamento (UE) 1303/2013-, donde se regulan con los papeles de la Comisión y de los Estados miembros en la ejecución de los fondos. 
de las cuestiones relativas a los fondos ${ }^{11}$. No se deja espacio para que los Estados miembros ejecuten los fondos con autonomía o de conformidad con su organización y procedimientos. Se regulan todos los aspectos y, lo que es más importante, se sujeta a los Estados a una estrecha supervisión por parte de la Comisión.

Un repaso superficial de la normativa vigente parece conceder libertad a los Estados para determinar cuáles son los procedimientos a seguir o las estructuras organizativas a utilizar. El REFIN, por ejemplo, contiene unas indicaciones relativas al régimen de gestión compartida que no concreta los métodos o las formas exactas a emplear: «... cuando se gestionen fondos de la Unión en régimen de gestión compartida los Estados miembros respetarán los principios de buena gestión financiera, transparencia y no discriminación y asegurarán la proyección pública de la acción de la Unión [...] al realizar las tareas relacionadas con la ejecución del presupuesto, los Estados miembros adoptarán todas las medidas necesarias, incluidas medidas legislativas, reglamentarias y administrativas, para proteger los intereses financieros de la Unión» ${ }^{12}$.

No obstante, si se va un paso más allá y se profundiza en la normativa específica de los fondos, se puede observar que la UE determina exactamente cómo deben ser las formas empleadas y los procedimientos a seguir. Constituyen ejemplo claro de ello los últimos considerandos del Reglamento (UE) 1303/2013, de disposiciones comunes. Ahí ya se anuncian ciertas obligaciones organizativas y procedimentales que, posteriormente, en ese mismo reglamento y en las normas específicas de cada fondo, se regulan aún más intensamente: «Es preciso que los Estados miembros designen una autoridad de gestión, una autoridad de certificación y una autoridad de auditoría funcionalmente independiente para cada programa operativo.... ${ }^{13}$.

En definitiva, se convierte a los Estados en una suerte de órganos propios de la UE que carecen de autonomía y se limitan a obedecer las previsiones contenidas en la normativa y las exigencias realizadas por la Comisión.

${ }^{11}$ Esto no es nuevo, desde el momento que los Estados intervienen en la ejecución del presupuesto de la UE, se producen lo que Moreno Molina ha descrito como «unas repercusiones tangibles en la organización de la Administración del Estado miembro, pues, en general han de establecerse órganos que gestionen específicamente esos recursos de los PGUE», Moreno Molina, A.M.: "Los medios económicos de la Administración...», ob. cit., p. 380.

12 Artículo 59 del REFIN.

${ }_{13}$ Considerando 106 del Reglamento (UE) 1303/2013, de disposiciones comunes. 


\section{EL PAPEL DE LOS ESTADOS MIEMBROS COMO MEROS GESTORES}

\section{EL «CÓMO» SE EJECUTAN LOS FONDOS: ORGANIZACIÓN Y PROCEDIMIENTOS a) Autoridades en la ejecución y control}

La primera manifestación de la intensa intervención de la UE se puede observar en las obligaciones que se imponen en materia de organización. Los reglamentos no solo contienen indicaciones generales acerca de cuestiones como la independencia que deben tener los organismos de control o la publicidad que debe darse a determinadas actividades, sino que imponen obligaciones concretas -composición de órganos, reglas de funcionamiento, procedimientos a seguir, etc.-.

En concreto, se prevé que para ejecutar los fondos europeos, los Estados miembros deben contar al menos con tres autoridades: una de gestión, una de certificación y una de auditoría ${ }^{14}$. Asimismo, se reconoce la posibilidad de disponer de los denominados organismos intermedios para que colaboren en la ejecución de los fondos ${ }^{15}$.

Como se puede observar, de entrada, se indica cuáles deben ser los organismos -autoridades-, pero, además, se determina qué características deben tener, qué funciones concretas deben desempeñar y conforme a qué procedimientos deben desarrollar su actividad. Por ejemplo, de acuerdo con el reglamento de disposiciones comunes, la autoridad de gestión es el organismo que se encarga, básicamente, de la gestión de uno o varios programas operativos, en adelante $\mathrm{PO}^{16}$. Puede tener

${ }^{14}$ Véanse los artículos 123 y siguientes del Reglamento (UE) 1303/2013, de disposiciones comunes.

15 Además de las autoridades mencionadas, se pueden designar organismos intermedios. Estos organismos se encargan de desarrollar tareas bajo la responsabilidad de las autoridades de gestión o certificación. El objetivo principal es la descentralización de determinadas acciones. Mediante los mismos se facilitan las tareas administrativas y se permite, por ejemplo, que un grupo de subvenciones sean gestionadas por un organismo distinto a la autoridad de gestión, pero bajo la supervisión de esta última. Para que un sujeto - público o privado- pueda ser designado organismo intermedio debe proporcionar garantías de su solvencia y su competencia en el ámbito de que se trate, al igual que de su capacidad administrativa y de gestión financieras. Es frecuente designar a Administraciones locales o autonómicas como organismos intermedios o incluso a fundaciones o empresas especializadas. A modo de ejemplo véase la designación de la Fundación Escuela de Organización Industrial como Organismo Intermedio para tramitar y conceder subvenciones en el marco de los Programas Operativos de Empleo Juvenil y de Empleo, Formación y Educación, del Fondo Social Europeo, y de los Programas Operativos de Crecimiento Sostenible y Crecimiento Inteligente, del Fondo Europeo de Desarrollo Regional, en el BOE de 14 de marzo de 2016 mediante Orden IET/326/2016, de 8 de marzo, por la que se autoriza a la Fundación Escuela de Organización Industrial a conceder subvenciones en el marco de los Programas Europeos del Fondo Social Europeo y del Fondo Europeo de Desarrollo Regional.

${ }^{16}$ Los PO son los documentos donde se concreta la ejecución de los fondos. Son elaborados por los Estados miembros. A modo de ejemplo puede observarse que, en Espańa, en el caso del FEDER se han aprobado PO de cooperación territorial -transnacional, transfronterizo, interregional-, PO regionales y $\mathrm{PO}$ plurirrregionales - de crecimiento inteligente, de crecimiento sostenible, de la inicia- 
carácter nacional, regional o incluso local. Esta autoridad asume un papel central en la gestión de los fondos puesto que es la que tiene la responsabilidad de ponerlos en marcha con independencia de que luego otras autoridades, supervisen su actividad. Se encarga de seleccionar las operaciones y de gestionar el PO y lleva parte del control y la gestión financiera. A modo de ejemplo, puede observarse que en España se ha designado como autoridad de gestión del Fondo Social Europeo a la Unidad Administradora del Fondo Social Europeo -UAFSE-.

La manifestación más clara de la intensa intervención por parte de la UE se puede observar en las autoridades de control. Se obliga a los Estados miembros a disponer de una autoridad de auditoría a la que se atribuyen todo tipo de funciones relacionadas con el control de la ejecución de los fondos ${ }^{17}$. Esta autoridad, como es lógico, debe ser independiente orgánica y funcionalmente de las autoridades de gestión y certificación. En España, la Intervención General de la Administración del Estado tiene atribuida esta función ${ }^{18}$.

La labor de este organismo es clave para la supervisión y control de los fondos europeos y se desarrolla en los términos que ha definido la normativa europea. No solo debe tener las características orgánicas que describe la normativa y realizar las actividades señaladas, sino que, además, en multitud de acciones está sujeta a supervisión de la Comisión. De esta forma se acrecienta aún más el control que ejerce la UE sobre el Estado. Un ejemplo claro de ello es la posibilidad que tiene la Comisión de supervisar la estrategia de auditoría ${ }^{19}$.

Además de las autoridades explicadas, la normativa también establece la obligación de crear un comité de seguimiento. En efecto, tras la aprobación de un PO el Estado debe crear un órgano -comité de seguimiento-, encargado de hacer el seguimiento de la ejecución del programa. Aunque el Estado decide quiénes lo integran, su composición viene preestablecida por los reglamentos, que exigen que esté integrado por representantes de las autoridades competentes del Estado miembro de que se trate, por representantes de los organismos intermedios y por representantes de las autoridades locales, de las autoridades regionales y de los interlocutores

tiva PYME, etc.-. Pueden consultarse en la web de la Dirección General de Fondos Comunitarios: http://www.dgfc.sgpg.meh.es/sitios/dgfc/es-ES/ipr/fcp1420/p/Paginas/inicio.aspx.

${ }_{17}$ Sirva de ejemplo la función de garantizar que se realizan las auditorías destinadas a comprobar el funcionamiento eficaz de los sistemas de gestión y control de los PO. Véase el art. 127 del Reglamento (UE) 1303/2013, de disposiciones comunes.

${ }_{18}$ Como ejemplo de su actividad en relación con los fondos europeos puede verse la Resolución de 5 de mayo de 2016, de la Secretaría de Estado de Presupuestos y Gastos, por la que se publica el Convenio de colaboración entre la Intervención General de la Administración del Estado y la Ciudad de Melilla para la realización de funciones de control en relación con el fondo europeo de desarrollo regional y el fondo de cohesión, publicada en el $B O E$ el 12 de mayo de 2016.

19 Tras la adopción de un PO, la autoridad de auditoría prepara una estrategia para realizar las auditorías - ahí se debe exponer la metodología de auditoría, el método de muestreo para auditar las operaciones y la planificación de auditorías en relación con el ejercicio contable en curso y los dos ejercicios contables siguientes, etc.-. Esta estrategia se debe presentar a la Comisión si se solicita. Se regula en el artículo 127.4 del Reglamento (UE) 1303/2013 de disposiciones comunes. 
económicos y sociales. Asimismo, las reglas de funcionamiento de este órgano están perfectamente descritas en la normativa europea ${ }^{20}$.

Como se puede observar, la regulación no establece unas indicaciones genéricas orientadas a garantizar la uniformidad en los Estados miembros, sino que define perfectamente los órganos con los que deben contar, su composición y funciones y, además, los sujeta a control y supervisión de la Comisión. En definitiva, los Estados miembros carecen de autonomía para escoger las estructuras organizativas empleadas para ejecutar y gestionar los fondos europeos.

\section{b) Las pautas procedimentales: el caso de los pagos}

La intensa intervención de la UE no solo se da en la vertiente orgánica de la ejecución de los fondos; los reglamentos también describen de forma pormenorizada los procedimientos a seguir por las Administraciones nacionales.

No se puede hablar de un procedimiento administrativo común aplicable a toda la ejecución, pero sí se pueden detectar numerosas pautas procedimentales. Los ejemplos son múltiples y se observan, sobre todo, cuando se describen las funciones que deben realizar las estructuras organizativas. Uno de los más claros es el relativo a los pagos -canalización de los recursos de los fondos a los Estados miembros y, posteriormente, a los receptores finales-. Este procedimiento se encuentra definido a lo largo de la normativa y permite observar cómo la UE no escatima a la hora de imponer trámites procedimentales de obligado cumplimiento ${ }^{21}$.

El sistema de pagos parte de dos ideas: la anticipación de los recursos a los receptores finales por parte de los Estados miembros -antes de recibir los recursos

${ }^{20}$ De acuerdo con los artículos 48 y siguientes del Reglamento (UE) 1303/2013, el comité de seguimiento debe reunirse por lo menos una vez al año y examinar la ejecución del programa y los avances en la consecución de sus objetivos. En su examen debe atender a los datos financieros, a los indicadores comunes y específicos del programa, en especial los cambios en los valores de los indicadores de resultados y los avances en la consecución de valores previstos cuantificados y, cuando proceda, a los resultados de los análisis cualitativos. Asimismo, debe examinar todas las cuestiones que afecten al rendimiento del programa. Este órgano puede formular observaciones a la autoridad de gestión acerca de la ejecución y evaluación del programa, incluidas acciones dirigidas a reducir la carga administrativa para los beneficiarios. Asimismo, la autoridad de gestión consultará al comité de seguimiento sobre la posible modificación del programa y será este el que decida si se puede modificar o no. Además de lo descrito, se obliga al comité a elaborar determinados informes para presentar a la Comisión. Para que la Comisión los admita deben contener las cuestiones que especifica la normativa. En caso de que se admita el informe realizado por el comité de seguimiento en cuestión, la Comisión lo examinará y transmitirá al Estado miembro sus observaciones en el plazo de dos meses a partir de la fecha de recepción de dicho informe, y en el plazo de cinco meses a partir de la fecha recepción del informe final de ejecución. Si la Comisión no hace ninguna observación en esos plazos, los informes se considerarán aceptados.

${ }^{21}$ Además del procedimiento relativo a los pagos, a lo largo de los reglamentos se pueden encontrar indicaciones procedimentales en relación con la aprobación de los documentos estratégicos, la corrección de irregularidades, la realización de determinadas actividades de auditoría, etc. 
de la UE-y la cofinanciación ${ }^{22}$. De acuerdo con esto, la financiación de actividades, acciones, objetivos o proyectos con cargo a los fondos es abonada inicialmente por los Estados miembros y, posteriormente, en virtud de la cofinanciación la UE reembolsa solo el porcentaje que corresponda en cada caso. Si, por ejemplo, el porcentaje de financiación en el Fondo Europeo de Desarrollo Regional -FEDER- para un proyecto es del $75 \%$, se solicitará el reembolso del $75 \%$ del coste total del proyecto.

Todo el procedimiento de pagos está perfectamente definido en el reglamento de disposiciones comunes y en algunos artículos de los reglamentos específicos. Es un procedimiento largo y complejo y, al igual que ocurre con los aspectos organizativos, apenas se deja espacio a los Estados miembros para tomar decisiones con autonomía o aplicar sus propias normas de procedimiento.

El comienzo del procedimiento de pago se produce con la aprobación de un PO, que es un acto que produce efectos financieros: «la decisión de la Comisión por la que se adopte un programa constituirá una decisión de financiación a efectos del artículo 84 del Reglamento financiero y, una vez notificada al Estado miembro de que se trate, el compromiso jurídico a efectos del citado Reglamento» ${ }^{23}$. Los compromisos presupuestarios de la Unión con respecto a cada PO se contraen por tramos anuales para cada fondo. Por ello, con independencia de que un Estado miembro tenga asignada una cantidad para el período 2014-2020, el sistema presupuestario funciona por años naturales, por lo que los compromisos de pago con cargo a los fondos se hacen siguiendo este esquema.

Los pagos revisten la forma de prefinanciación inicial, pagos intermedios y pago del saldo final. La prefinanciación inicial se abona una vez que la Comisión aprueba el PO por la que se adopte el programa. Este pago abarca todo el período de programación -superior a un año- ${ }^{24}$. El importe recibido por este concepto solo

${ }^{22}$ La cofinanciación implica que las acciones no se financian íntegramente con cargo a los fondos: un porcentaje del coste correrá a cargo del Estado miembro -o, en su defecto, de la Comunidad Autónoma o Entidad Local-. El objeto de este principio es «garantizar la apropiación de las políticas sobre el terreno", esto es, conseguir que el Estado miembro se implique y asuma parte de responsabilidad en las políticas y acciones fomentadas por la Unión integrándolas como propias. El porcentaje de actividad financiado con cargo al fondo europeo dependerá de la categoría de desarrollo de la región, que se determinará en el AA. A modo de ejemplo puede observarse que en el AA de España 2014-2020, las regiones se clasifican en las siguientes categorías: «más desarrolladas», "en transición» $\mathrm{y}$ «menos desarrolladas». Estas categorías vienen determinadas por cuestiones como los niveles de empleo, la formación, la pobreza, el PIB, etc. En las regiones con mayor nivel de desarrollo el porcentaje de financiación con cargo a la UE es inferior que en aquellas menos desarrolladas, en las que el porcentaje de financiación con cargo a la UE suele rondar el $80 \%$. En suma, a menos desarrollo, más ayuda de la UE. Sobre esto véanse los considerandos 26 y 105 del Reglamento (UE) 1303/2013, de disposiciones comunes.

${ }^{23}$ El artículo 84 Reglamento (UE) 966/2012, sobre las normas financieras aplicables al presupuesto general de la Unión, establece que «el compromiso del gasto irá precedido de la adopción de una decisión de financiación por parte de la institución o las autoridades en las que esta haya delegado competencias».

${ }^{24}$ Los tramos y porcentajes de pago de la prefinanciación inicial se encuentran previstos en el artículo 134 del Reglamento (UE) 1303/2013 de disposiciones comunes. 
se puede emplear para abonar los pagos a los beneficiarios relacionados con la ejecución del programa. Para ello, se pone inmediatamente a disposición del organismo responsable. El importe pagado como prefinanciación inicial se liquida totalmente de las cuentas de la Comisión, a más tardar, cuando se cierre el PO.

Respecto a los pagos intermedios y de saldo final son las normas específicas de los fondos las que establecen los requisitos para el cálculo del importe reembolsado por esos conceptos, por lo que se pueden encontrar algunas variaciones. Ese importe se calcula en función del porcentaje de cofinanciación específico aplicable al gasto ${ }^{25}$. Para realizar los pagos intermedios, la autoridad de certificación debe presentar periódicamente una solicitud de pago que comprenda los importes anotados en su sistema contable en ese ejercicio. No obstante, podrá incluir tales importes, cuando lo considere necesario, en las solicitudes de pago presentadas en los siguientes ejercicios contables - por ejemplo, cuando haya un exceso de gasto- ${ }^{26}$. El saldo final se pagará, a más tardar, en el plazo de tres meses tras la fecha de la aceptación de las cuentas del último ejercicio contable, o en el plazo de un mes tras la fecha de aceptación del informe de ejecución final si esta fecha es posterior ${ }^{27}$.

Lo descrito solo son unas pinceladas de la extensa regulación del procedimiento de pagos y constituye una muestra de que la intensidad normativa también afecta a cuestiones procedimentales. La UE impone multitud de obligaciones a las Administraciones nacionales y condiciona a los Estados a la hora de decidir aspectos como, por ejemplo, la forma y el momento en que se abonan los recursos a los beneficiarios. Se limita, en definitiva, la autonomía para gastar los recursos de los que son receptores. El Estado se convierte en un mero gestor, con una capacidad de decidir muy reducida.

\section{El «PARA QUÉ» SE UTILIZAN LOS RECURSOS: LOS DOCUMENTOS ESTRATÉGICOS QUE LO EXPLICAN}

Dado que los fondos se emplean para financiar multitud de actividades y que cada Estado tiene sus prioridades -condicionadas por su grado de desarrollo o su nivel de integración en la UE-, la normativa prevé que los Estados receptores

25 El propio reglamento de disposiciones comunes establece las normas específicas en relación a este tema para los fondos EIE se encuentra prevista en los artículos 131 y siguientes. Se excluye de la aplicación de estos preceptos el Feader, cuyo sistema de pagos es el previsto para los fondos de la Política Agrícola Común -Reglamento (UE) 1306/2013 sobre financiación, gestión y seguimiento de la PAC-.

${ }^{26}$ Estas solicitudes deben incluir el importe total del gasto subvencionable en que hayan incurrido los beneficiarios al ejecutar las operaciones, según figure en el sistema contable de la autoridad de certificación, y el importe total del gasto público para la ejecución de las operaciones. El gasto subvencionable incluido en una solicitud de pago debe estar documentado con facturas pagadas o documentos contables de valor probatorio equivalente, excepto si se trata de las formas de ayuda simplificadas -sistemas que simplifican las cargas administrativas. En estos sistemas no se abona cada euro gastado, sino que hace un cálculo del gasto realizado, por ejemplo, por medio de estimaciones-.

27 Véanse los artículos 134 y 138 del Reglamento (UE) 1303/2013, de disposiciones comunes. 
deben elaborar unos documentos estratégicos que sirven para concretar cómo va a ser la ejecución de los fondos europeos.

Aunque formalmente los Estados deciden cómo van a gastar los recursos, esta elección se hace dentro del Marco Estratégico Común, en adelante $\mathrm{MEC}^{28}$, que establece unos principios y objetivos dentro de los cuales deben moverse los Estados. Todas las decisiones que se adopten dentro de ese marco, además, deben explicarse en documentos estratégicos que son supervisados por la Comisión, la cual puede formular reparos u objeciones.

Esos documentos estratégicos son el Acuerdo de Asociación -AA- y los programas operativos - PO-. El AA responde al principio de gobernanza en varios niveles - basado en la participación de los socios de los Estados miembros a la hora de diseñar la gestión y ejecución de los fondos-. Este documento traduce los elementos del MEC al contexto nacional y establece compromisos firmes para conseguir los objetivos de la Unión a través de la programación de los fondos. Posee elementos esenciales, que se someten a la decisión de la Comisión, y otros que no requieren dicha decisión y pueden ser modificados por el Estado miembro. Abarca todas las ayudas de los fondos en el Estado miembro, es decir, es un único documento para un período y para todos los fondos. Basándose en el MEC, para el período 20142020 , cada Estado ha elaborado un $\mathrm{AA}^{29}$. A modo de ejemplo puede observarse que el AA de España para el período 2014-2020 se aprobó el 4 de noviembre de 2014. Se define como «un documento elaborado por un Estado miembro, con participación de socios y según el enfoque de una gobernanza en varios niveles, en el que se expone la estrategia de ese Estado miembro, las prioridades y disposiciones para utilizar los Fondos EIE de una manera efectiva y eficiente para perseguir la estrategia de la Unión para un crecimiento inteligente, sostenible e integrador, y que la Comisión aprueba tras evaluarlo y dialogar con el Estado miembro de que se trate».

Los programas operativos - $\mathrm{PO}-$ son los documentos donde se concreta la ejecución de los fondos y constituyen la base para la ejecución del crédito presupuestario correspondiente. Su contenido viene determinado por el artículo 27 del Reglamento (UE) 1303/2013. Básicamente es el instrumento empleado para definir cómo se va

${ }^{28}$ El Marco Estratégico Común-MEC-es un documento, incorporado en forma de anexo al Reglamento (UE) 1303/2013, que tiene por objeto establecer unos principios rectores para facilitar el proceso de programación y la coordinación sectorial y territorial de la intervención de la Unión con cargo a los fondos EIE y con otros instrumentos y políticas europeos pertinentes en consonancia con las metas y los objetivos de la estrategia de la Unión. Este documento establece un marco para facilitar la preparación del Acuerdo de Asociación y los Programas Operativos con arreglo a los principios de proporcionalidad y subsidiariedad, y teniendo en cuenta las competencias nacionales y regionales para decidir sobre la política específica y adecuada y las medidas de coordinación. Véase el artículo 5 y el anexo I del Reglamento (UE) 1303/2013.

${ }^{29}$ De acuerdo con la normativa, este documento se elabora en colaboración con las autoridades locales y regionales, los interlocutores económicos y sociales y los organismos pertinentes representantes de la sociedad civil, incluidos los interlocutores medioambientales, las organizaciones no gubernamentales y los organismos encargados de promover la inclusión social, la igualdad de género y la no discriminación -artículo 5.2 del Reglamento (UE) 1303/2013-, de disposiciones comunes. 
a gastar un fondo concreto en un territorio determinado o para explicar cómo se va a conseguir un objetivo por medio del fondo. Es el instrumento de ejecución por excelencia. Su elaboración corresponde a los Estados miembros en colaboración con los mismos sujetos que intervienen en el AA y deben ser presentados a la Comisión. Funcionan como una propuesta de gasto específica que realiza el Estado que, de ser aprobada por la Comisión, produce efectos financieros. A modo de ejemplo, puede observarse que en el caso del FEDER se han aprobado PO de cooperación territorial -transnacional, transfronterizo, interregional-, PO regionales y PO plurirregionales -de crecimiento inteligente, de crecimiento sostenible, de la iniciativa PYME, etc.-Si se analiza un programa específico, se pueden contemplar las acciones concretas a desarrollar. Por ejemplo, en el apartado 2.A.6 del PO del FEDER para Andalucía -2014-2020-, se prevé el desarrollo de acciones determinadas que se van a financiar con cargo al fondo.

La obligación de los Estados de describir lo que van a hacer con los fondos en los documentos señalados pone el broche final a la dirección y control de la UE en general y de la Comisión en particular. En este ámbito la autonomía de los Estados receptores se reduce únicamente a escoger aquellas actividades que encajen en las exigencias contenidas en el MEC, en los reglamentos y en aquellas cuestiones planteadas por la Comisión.

\section{EL MITO DE LA AUTONOMÍA DE LOS ESTADOS MIEMBROS}

\section{LA REDUCCIÓN A MÍNIMOS DE LOS PRINCIPIOS DE SUBSIDIARIEDAD Y PROPOR- CIONALIDAD}

Como ha quedado expuesto, los reglamentos europeos describen cada uno de los detalles relativos a la ejecución de los fondos. Desde los aspectos más generales de la organización hasta las cuestiones más concretas de las acciones a financiar, todo está perfectamente regulado. En general, los Estados están sujetos a todo tipo de obligaciones cuyo incumplimiento daría lugar, en última instancia, a una pérdida de los recursos. Todas esas obligaciones ponen en entredicho la vigencia y operatividad de los principios de subsidiariedad y proporcionalidad.

El principio de subsidiariedad ${ }^{30}$ se encuentra contemplado en el TFUE. En virtud del mismo, «en los ámbitos que no sean de su competencia exclusiva, la Unión intervendrá sólo en caso de que, y en la medida en que, los objetivos de la acción

30 Para una explicación del principio de subsidiariedad véase Carro Martínez, A.: «La Unión Europea y el principio de subsidiariedad», RAP, núm. 126, 1991, pp. 217-252; Rodríguez-Arana Muñoz, X.: «Sobre el principio de subsidiariedad», Noticias de la Unión Europea, núm. 110, 1994, pp. 11-42; Ortiz Díaz, J.: «El principio de subsidiariedad y la Unión Europea», Anuario de derecho europeo, núm. 4, 2004, pp. 63-72; Martínez López-Muñiz, J.L.: «El principio de subsidiariedad», Santamaría Pastor, J.A. (dir.): Los principios juridicos del Derecho Administrativo, La Ley, 2010, pp. $1275-1310$. 
pretendida no puedan ser alcanzados de manera suficiente por los Estados miembros, ni a nivel central, ni a nivel regional y local, sino que, debido a la dimensión o a los efectos de la acción pretendida, puedan alcanzarse mejor a escala de la Unión». Este principio, a su vez, va de la mano del principio de proporcionalidad, que determina que el contenido y la forma de la acción de la Unión «no excederán de lo necesario para alcanzar los objetivos de los Tratados»" ${ }^{31}$.

Pues bien, de acuerdo con el considerando 129 del Reglamento (UE) 1303/2013, los fondos europeos son uno de esos ámbitos donde se requiere una intervención de la UE para alcanzar los fines perseguidos. Ello sirve para justificar la regulación europea de determinadas cuestiones, pero no la excesiva intervención. Pese a ello, el mismo considerando señala que el reglamento «no excede de lo necesario para alcanzar dicho objetivo ${ }^{32}$.

Ahora bien, tras la explicación realizada anteriormente, esto debe ser cuestionado. Salvo que fuera necesario que todos los Estados miembros gestionen y ejecuten exactamente igual los fondos europeos, no puede considerarse que se respeten estrictamente ambos principios. La extensión de la intervención europea en materia de fondos permite dudar de que la regulación sea la estrictamente necesaria para conseguir los objetivos.

Por un lado, es cuestionable que todos los aspectos contenidos en los reglamentos no puedan ser regulados por los Estados para conseguir los objetivos -subsidiariedad-. Por otro, no puede considerarse que la intervención europea sea la estrictamente necesaria. En determinados casos es excesiva y, por tanto, desproporcionada - proporcionalidad-.

En efecto, con los reglamentos de los fondos no solo se persigue corroborar que se cumplen los objetivos fijados, sino que, con el pretexto de conseguir precisamente eso, se regula todo.

Es cierto que numerosas cuestiones requieren una regulación general europea, pero el grado de detalle con el que se interviene en todas las vertientes de los fondos -organización, pagos, irregularidades, formas de ayuda, documentos estratégicos, objetivos, sujetos intervinientes, etc.- permite afirmar que la única finalidad de esta exhaustiva regulación no es otra que conservar el control sobre todo aquello que tenga que ver con la ejecución, gestión y control.

${ }^{31}$ Ambos principios se encuentran en el artículo 5 de la versión consolidada del Tratado de la Unión Europea y del Tratado de Funcionamiento de la Unión Europea.

32 Considerando 129 del Reglamento (UE) 1303/2013, de disposiciones comunes: «Dado que el objetivo del presente Reglamento, a saber, reforzar la cohesión económica, social y territorial, no puede ser alcanzado de manera suficiente por los Estados miembros, sino que, debido a la magnitud de las disparidades existentes entre los niveles de desarrollo de las diferentes regiones y al retraso de las regiones menos favorecidas, así como a la limitación de los recursos financieros de los Estados miembros y de las regiones, puede lograrse mejor a escala de la Unión, esta puede adoptar medidas, de acuerdo con el principio de subsidiariedad establecido en el artículo 5 del TUE. De conformidad con el principio de proporcionalidad establecido en el mismo artículo, el presente Reglamento no excede de lo necesario para alcanzar dicho objetivo». 
Tal y como quedó apuntado, el paso a la gestión compartida conllevaría una pérdida del control sobre determinados asuntos que antes se gestionaban directamente por la Comisión. No obstante, la UE, lejos de aceptar esa situación, hizo una regulación detallada con el único fin de no perder el control y la dirección. Por ello, sí que podría considerarse que tal intervención es innecesaria en muchos aspectos $y$, en algunas cuestiones, excesiva. En consecuencia, puede afirmarse que pese a lo contenido en el considerando 129, los reglamentos de los fondos reducen a mínimos el respeto al principio de subsidiariedad y rompen, en determinadas cuestiones, con el principio de proporcionalidad.

\section{LA FICCIÓN DEL PRINCIPIO DE AUTONOMÍA INSTITUCIONAL Y PROCEDIMENTAL}

Otro de los principios que parece verse afectado con la amplia regulación de los fondos europeos es el de autonomía institucional y procedimental. De acuerdo con este principio, los Estados miembros preservan su libertad para escoger las estructuras organizativas y los procedimientos a la hora de ejecutar el Derecho de la UE ${ }^{33}$.

A diferencia de los anteriores, este principio no se encuentra regulado en la normativa, sino que ha sido extraído de la jurisprudencia, que se refiere al mismo implícitamente. Muestra de ello fue la Sentencia Fleischkontor, de 1971, que reconoció que cuando las autoridades nacionales fueran responsables de la aplicación del Derecho europeo, dicha aplicación se realizaría respetando las formas y procedimientos del Derecho nacional ${ }^{34}$. Posteriormente, el Tribunal de Justicia matizó que debía conciliarse con la aplicación uniforme del Derecho de la UE ${ }^{35}$.

La doctrina se ha hecho eco del mismo, no sin dificultades, puesto que ha sido entendido de distintas formas. En principio, la idea que parece transmitirse cuando se menciona este principio, es que los Estados poseen siempre una parcela en la que pueden escoger formas y procedimientos para ejecutar el Derecho de la UE. Ahora bien, si se analiza tanto la normativa relativa a los fondos europeos como la de otros

33 En relación con este principio véase Parejo Alfonso, L.: «El principio de la autonomía institucional y procedimental de los Estados miembros de la Unión Europea», Revista de Direito Administrativo \& Constitucional, núm. 50, 2012, pp. 172-204; Arzos Santisteban, X.: «La autonomía institucional y procedimental de los Estados miembros en la Unión Europea: mito y realidad", RAP, núm. 191, 2013, pp. 159-197.

${ }^{34}$ Sentencia del Tribunal de Justicia de 11 de febrero de 1971, Fleischkontor GmbH contra Hauptzollamt Hamburg-St. Annen, 39/70: «Where national authorities are responsible for implementing a community regulation it must be recognized that in principle this implementation takes place with due respect for the forms and procedures of national law».

35 Sentencia del Tribunal de Justicia del 6 de junio de 1972, Schlüter \& Maack v Hauptzollamt Hamburg-Jonas, 94/71: «As in the present case -it is for the national authorities to implement a community regulation; such implementation must as a matter of principle be carried out in accordance with the rules of form and procedure of national law. This principle of law must be reconciled with the need to apply community law uniformly so as to avoid unequal treatment». 
sectores, es fácil observar cómo se incumple sistemáticamente ${ }^{36}$. Es frecuente que la UE intervenga determinando cómo debe ser la organización o el procedimiento a seguir. No está claro qué aspectos se reservan al Estado o en qué casos se puede intervenir. Por ello, se ha considerado que es un principio rodeado de falta de claridad ${ }^{37}$.

En el caso de los fondos europeos, que es lo que aquí interesa, la doctrina expresa que su ejecución descansa sobre este principio pero que, en determinadas cuestiones, se encuentra limitado por el alcance de la normativa europea ${ }^{38}$. Ahora bien, si esto es así, la pregunta que procede realizarse es cómo opera este principio y hasta dónde puede intervenir el legislador europeo. Es decir, cuál es el espacio en materia procedimental y orgánica prohibido para el legislador europeo, si es que lo hay.

La realidad es que tras haber analizado la normativa europea, se puede afirmar con contundencia que la intervención en cuestiones organizativas y procedimentales no es puntual o excepcional, sino que es frecuente y exhaustiva. Por ello, es posible considerar, tal y como ya han defendido determinados sectores, que este principio está vacío de contenido y que se trata de una noción discutible ${ }^{39}$.

${ }^{36}$ Además de los fondos EIE, se pueden señalar multitud de sectores donde la UE ha desarrollado procedimientos obligatorios para los Estados miembros. Ejemplo de ello son el Reglamento (UE) 1308/2013 del Parlamento Europeo y del Consejo, de 17 de diciembre de 2013, por el que se crea la organización común de mercados de los productos agrarios, o el Reglamento (UE) 2017/1001 del Parlamento Europeo y del Consejo, de 14 de junio de 2017, sobre la marca de la Unión Europea. De estos y otros ejemplos da cuenta el trabajo de Mir Puigpelat, O.: «Razones para una codificación general del procedimiento de la Administración de la Unión» en la obra colectiva coordinada por Fuertes López, M.: Un procedimiento administrativo para Europa, Thomson Reuters-Aranzadi, 2012, pp. 131-165; también Viñuales Ferreiro, S.: El procedimiento administrativo de la Administración Europea, Thomson Reuters-Aranzadi, 2015; en el mismo sentido, Martin Delgado, I.: «El procedimiento administrativo en el Derecho de la Unión Europea», Revista de Derecho de la Unión Europea, núm. 19, pp. 99-143. Este autor señala que el principio de autonomía institucional se está viendo matizado por algunas normas sectoriales y cita como ejemplo la Directiva 2006/123/CE del Parlamento y del Consejo, de 12 de diciembre de 2006, relativa a los servicios en el mercado interior, «que obliga a los Estados miembros a cooperar con otros Estados miembros (asistencia mutua), a simplificar procedimientos administrativos, a crear puntos de acceso único y a establecer disposiciones relativas a determinados aspectos internos del procedimiento (derecho de información, empleo de medios electrónicos, plazos máximos para tramitar solicitudes, etc.)».

37 «La causa de que ello sea así radica en que no se encuentra proclamado como tal en norma escrita (desde luego en ninguna de Derecho originario o de los Tratados) en cuanto resultado más bien del empleo por el Tribunal de Justicia...», Parejo Alfonso, L.: «El principio de la autonomía institucional y procedimental...» ob. cit., pp. 172-173.

${ }^{38}$ Para Ordoñez Solís, «la gestión de los fondos europeos se lleva a cabo por los Estados miembros de acuerdo con el principio de autonomía institucional y procedimental. No obstante, la regulación europea ha modelado paulatinamente los órganos administrativos estableciendo una cierta homogeneidad en esta ejecución o gestión compartida por la Comisión Europea y las autoridades nacionales», en Ordońez Solís, D.: «La gestión de los...», ob. cit., p. 134. En el mismo sentido, aunque referido a otros sectores, se hace referencia a una «modulación» del principio de carácter «excepcional», en Parejo Alfonso, L.: «El principio de la autonomía...», ob. cit., p. 202.

39 Respectivamente, Mir Puigpelat, O.: «La Codificación del procedimiento administrativo en la Unión Europea», Velasco, Schneider (coord.): La unión administrativa europea, Marcial Pons, 2008, p. 59 y ss.; Arzos Santisteban, X.: «La Autonomía Institucional...», ob. cit., p. 160. 
En efecto, tal y como ya ha planteado un sector doctrinal, la autonomía institucional no es un verdadero principio que oriente la ejecución del Derecho de la UE. No se encuentra regulado en la normativa y la jurisprudencia de décadas recientes no se ha hecho eco expreso ni implícito del mismo. La extensa intervención en materia de procedimientos u organización no es un problema puntual que afecte a los fondos europeos, es una cuestión habitual que afecta a multitud de sectores. Los únicos principios que realmente van a delimitar la intervención de la UE en los términos descritos son los de subsidiariedad y proporcionalidad.

Por tanto, por mucho que se afirme que la ejecución de los fondos se asienta sobre este principio, no se puede aseverar que opere ni que rija la ejecución del Derecho de la UE, ni en los fondos ni en otros sectores. Ello no quiere decir que los Estados miembros no tengan autonomía para escoger las formas y procedimientos para ejecutar del Derecho de la UE, pero ello estará supeditado a que la UE no regule expresamente cómo debe desarrollarse una actividad -orgánica y procedimentalmente-. Solo en ese plano puede entenderse que este principio despliega sus efectos.

\section{OTRA MANIFESTACIÓN DEL DEBILITAMIENTO DE LA AUTONOMÍA DE LOS ESTADOS MIEMBROS: LA VINCULACIÓN DE LOS FONDOS A LA GOBERNANZA ECONÓMICA}

La reciprocidad implícita en los fondos europeos a la que antes se hacía referencia los convierte en mecanismos idóneos para imponer obligaciones a los Estados receptores. Esta idea se ha acentuado en el último período (2014-2020). Esta etapa comenzó en un contexto de profunda crisis económica. Por ello, cuando se tramitaron y aprobaron los nuevos reglamentos se conectó la política de cohesión con la gobernanza económica de la UE. En concreto, se vinculó la recepción de fondos europeos a los rescates y ayudas económicas recibidas por los Estados integrantes de la UE.

Por primera vez los fondos comenzaron a desempeñar funciones orientadas a solventar los problemas económicos de los Estados miembros. La finalidad de los mismos nunca ha sido dar apoyo a las dificultades económicas de los Estados; siempre se han centrado en favorecer la cohesión de la UE y el desarrollo en determinados ámbitos. Sin embargo, dado que desde 2008 se comenzaron a adoptar numerosas medidas para afrontar la crisis, en el siguiente período se vincularon los fondos a la gobernanza económica ${ }^{40}$. Con este nuevo enfoque no solo se perseguía dar coherencia al sistema y reorientar los recursos cuando fuera necesario; también

40 Sobre esto véase Fuentetaja Pastor, J.: Derecho administrativo..., ob. cit., p. 534 y ss. 
se buscaba presionar a los Estados para cumplir los compromisos adoptados en el marco de los programas de ajuste económico ${ }^{41}$.

Las medidas que vinculan los fondos a la gobernanza económica se encuentran previstas en los artículos 23 y siguientes del Reglamento 1303/2013: a) modificación del acuerdo de asociación y de los programas operativos a instancia de la Comisión; b) incremento del porcentaje de cofinanciación; y c) asistencia técnica. Solo la segunda y la tercera se pueden considerar mecanismos de ayuda a los Estados miembros; la primera, en cambio, habilita un conjunto de herramientas que más que de ayuda se pueden considerar se control o intervención ${ }^{42}$.

En efecto, la primera de las medidas previstas permite que la Comisión, por recomendación del Consejo, solicite a un Estado miembro que modifique su acuerdo de asociación -AA- y sus programas operativos - PO-. La finalidad es adaptar estos documentos a recomendaciones económicas del Consejo para maximizar el impacto de los fondos en los Estados que reciban ayuda financiera ${ }^{43}$. La idea es que el Estado modifique la documentación para ajustarse a las exigencias de la Comisión -previa recomendación del Consejo-.

${ }^{41}$ Se consideran sujetos a un programa de ajuste los Estados que, por ejemplo, fueron receptores de recursos en el marco del mecanismo de ayuda financiera a la balanza de pagos -apoyo a la balanza de pagos-. Este instrumento se ha puesto en marcha en numerosas ocasiones. Algunos de los receptores han sido Rumanía, Hungría y Letonia. A modo de ejemplo puede observarse que en el caso de Hungría el programa se puso en marcha en 2009 y se concedió una cuantía de 6500 millones de euros a través del mecanismo de ayuda a la balanza de pagos que fue apoyada por un préstamo del Fondo Monetario Internacional por importe aproximado de 12500 millones de euros y una ayuda del Banco Mundial de 1000 millones de euros. Respectivamente, Decisión del Consejo de 22 de octubre de 2013 por la que se concede asistencia mutua a Rumanía (2013/532/UE); Decisión del Consejo de 22 de octubre de 2013 por la que se concede a Rumanía una ayuda financiera a medio plazo de carácter preventivo de la Unión (2013/531/UE); Decisión del Consejo de 4 de noviembre de 2008 por la que se concede ayuda financiera comunitaria a medio plazo a Hungría (2009/102/CE); y Decisión del Consejo de 20 de enero de 2009 por la que se concede asistencia mutua a Letonia (2009/289/CE).

${ }^{42}$ Las otras medidas previstas sí son de ayuda. A modo de ejemplo puede observarse que una de las contenidas en la normativa permite incrementar el porcentaje de financiación con cargo a la UE. Tal y como se explicó anteriormente, las acciones financiadas con cargo a los fondos se cofinancian, es decir, solo una parte se abona con cargo a los fondos; el resto lo asume el Estado miembro. Pues bien, el reglamento de disposiciones comunes prevé la posibilidad de incrementar el porcentaje de cofinanciación cuando un Estado se encuentre en un programa de ajuste -a petición de del Estado-, en diez puntos porcentuales por encima del porcentaje de cofinanciación aplicable a cada prioridad, en el caso del FEDER, el FSE y el Fondo de Cohesión, o a cada medida, en el caso del Feader y el FEMP. El fin último de esta previsión es descargar el gasto que supone para el Estado percibir fondos europeos. En este caso, es una medida de ayuda más que de intervención o control.

${ }^{43}$ En este último supuesto el Estado miembro debe cumplir una de las siguientes condiciones previstas en el artículo 23: se ha puesto a su disposición ayuda financiera de la Unión de conformidad con el Reglamento (UE) 407/2010 del Consejo (30); se ha puesto a su disposición ayuda financiera de conformidad con el Reglamento (CE) 332/2002 del Consejo (31); se ha puesto a su disposición ayuda financiera que desencadena un programa de ajuste macroeconómico de conformidad con el Reglamento (UE) 472/2013 del Parlamento Europeo y del Consejo (32) o una decisión del Consejo de conformidad con el artículo 136, apartado 1, del TFUE. 
Cuando el Estado no adopte medidas eficaces en respuesta a la solicitud de la Comisión, esta podrá proponer al Consejo que suspenda una parte o la totalidad de los pagos correspondientes a los programas o prioridades afectados. No obstante, cuando proceda, podrán tenerse en cuenta circunstancias excepcionales de un Estado miembro, como, por ejemplo, la contracción de su PIB real durante dos o más años consecutivos anteriores a la solicitud de reprogramación ${ }^{44}$.

Como se puede observar, la modificación de los documentos estratégicos no es una medida de ayuda a los Estados miembros, más bien es una medida de control o intervención que permite a la UE imponer obligaciones bajo la amenaza de suspender los pagos. Es cierto que el establecimiento de este tipo de medidas permite dar coherencia a toda la financiación recibida desde la UE. No obstante, también es cierto que la finalidad de los fondos nunca ha sido la de solucionar problemas económicos generales de los Estados receptores, sino que siempre han estado vinculados únicamente a la cohesión económica y social.

Una de las cuestiones que permiten afirmar que esta medida es de control y no de ayuda opcional para un Estado es que se establece de forma coercitiva. Los Estados deben aceptarla obligatoriamente. De esta forma, cuando estén sujetos a un programa de ajuste económico no solo deberán cumplir con las exigencias derivadas del mismo, normalmente contenidas en un acuerdo -Memorando de Entendimiento-, sino que deberán atender los requerimientos vinculados a fondos europeos. Esto puede llevarlos a tener que modificar sus documentos estratégicos y, en definitiva, a gastarse los recursos tal y como indican la Comisión y, en su caso, el Consejo.

Por consiguiente, cabe afirmar que lo que subyace bajo algunas de estas medidas vinculadas a la gobernanza económica no solo son mecanismos de ayuda: son medidas de intervención, control y dirección que aprovechan la reciprocidad contenida en los fondos para imponer obligaciones a los Estados miembros.

\section{CONCLUSIONES}

La fuerte europeización de las Administraciones nacionales es un hecho objetivo e indiscutible. Los fondos europeos no son más que una muestra de ello.

Actualmente, el proceso de integración está tan avanzado que las normas vigentes no solo persiguen una aplicación uniforme del Derecho europeo; también establecen mecanismos para conseguir una interpretación y ejecución idéntica en todos los Estados miembros. Ello no solo pasa por regular cuestiones que afectan a la organización y procedimientos internos, sino por someter esa aplicación del Derecho de la UE a un control permanente.

${ }^{44}$ La normativa no establece ningún calendario específico para que la Comisión adopte la propuesta de levantar la suspensión de pagos una vez que el Estado miembro haya adoptado medidas eficaces. En cualquier caso, adoptará la propuesta inmediatamente después de la aprobación del acuerdo de asociación y de los programas revisados. 
En el caso de los fondos, esa tendencia a intervenir intensamente ha alcanzado su máximo tras la crisis económica. La sujeción de los Estados miembros a programas de ajuste económico, unida a la necesidad de acceder a los recursos canalizados por los fondos, los aboca a acatar directrices en cuestiones que antes regulaban de forma autónoma. La UE no solo regula todas las cuestiones relacionadas con la gestión y control de los fondos europeos, sino que también impone obligaciones a los Estados que nada tienen que ver con los fines perseguidos por los fondos.

Esa fuerte intervención puede ser discutida por innecesaria o contraria a los principios de subsidiariedad y proporcionalidad, pero lo cierto es que no es excepcional. Se enmarca en la tendencia a unificar los ordenamientos de los Estados miembros en aras de la consecución de objetivos comunes. Materias como la contratación pública ya han dejado de pertenecer a la esfera de autonomía de los Estados y han pasado a estar perfectamente delimitadas por la UE. Asimismo, se pueden señalar multitud de cuestiones, como, por ejemplo, el procedimiento administrativo, en las que se trabaja intensamente tratando de buscar elementos comunes con el fin último de garantizar la interpretación y aplicación uniforme del Derecho europeo ${ }^{45}$.

En definitiva, las relaciones con la UE ya no se caracterizan por una intervención mínima o subsidiaria. Esto facilita la aplicación del Derecho europeo, pero también pasa por restar autonomía a los Estados miembros y por acomodar las normas y costumbres nacionales a las exigencias europeas.

ReCiBido: febrero de 2018, aCEPTADO: abril de 2018

45 Sobre la intervención europea en contratación pública, vid., por todos, los trabajos del X Congreso Asociación Española Profesores de Derecho Administrativo de Gimeno Feliu, J.M., Gallego Córcoles, I., Moreno Molina, J.A. y Hernández González, F.L.: Las nuevas directivas de contratación pública, Aranzadi, 2015. Sobre el procedimiento administrativo europeo véase Viñuales Ferreiro, S.: El procedimiento administrativo..., ob. cit.; también los trabajos de obra colectiva coordinada por Fuertes López, M.: Un Procedimiento Administrativo..., ob. cit. 
